\title{
Dependence of Static Fatigue Tests on Experimental Configuration for a Crystalline Rock
}

\author{
James Kear ${ }^{1, a *}$ and Andrew P. Bunger ${ }^{2, b}$ \\ ${ }^{1}$ CSIRO Earth Science and Resource Engineering, Melbourne, Australia \\ ${ }^{2}$ Department of Civil and Environmental Engineering, University of Pittsburgh, Pittsburgh, PA, USA \\ ajames.kear@csiro.au, ${ }^{\mathrm{b}}$ bunger@pitt.edu
}

Keywords: Static fatigue; Rock strength; Laboratory testing

\begin{abstract}
This paper presents static fatigue laboratory experiments conducted in three different configurations. The experiments are designed so as to cause delayed tensile failure in dry Gabbro specimens after the sustained application of a static subcritical load. Results from the static fatigue experiments give a time to failure of the specimen related to the applied static load. In the presented experiments, results spanning up to six orders of magnitude of time to failure were collected for three-point bending, four-point bending, and indirect tensile (Brazilian) specimens. The data supports an exponential relationship between tensile stress and time to failure, noting that a power law relationship is also supported by the data. The salient difference among the configurations is hypothesized to be the size of the region of the specimen that is subjected to a close approximation of the maximum tensile stress. The time to failure at a given nominal tensile stress, the decrease in time to failure associated with a given increase in stress (i.e. the slope in a semi logarithmic plot), and the magnitude of the scatter of the data about the best-fit curve are all observed to correlate inversely with the nominal size of the region subjected to the maximum tensile stress.
\end{abstract}

\section{Introduction}

Static fatigue is the delayed failure of a brittle material subjected to a sustained static (in contrast to cyclic) load that is insufficient to generate instantaneous failure. Rocks are well-known to exhibit static fatigue, and this phenomenon is understood to be fundamental to the mechanics of earthquakes and failure of rocks that are subjected to mining induced stresses [1]-[3]. However, in spite of the fact that it is well-known that the measured tensile strength of rocks [4], [5] and cyclic fatigue properties of asphalt from laboratory experiments depends upon the testing configuration, the dependence of tensile static fatigue behavior of rocks on the testing configuration has not been systematically evaluated in the laboratory.

Cocurullo et al. [6] compare cyclic fatigue behavior of asphalt under indirect tensile (Brazilian) and four-point bending loading, finding that indirect tension produces a shorter fatigue life that fourpoint bending in laboratory specimens.

Some relevant studies comparing tensile strength of rock/rock-like materials for different loading configurations include [4], which identifies that, for plaster of Paris, the tensile strength given by three-point or four-point beam tests are frequently higher than those obtained by direct tension testing by a ratio of 2.3:1. In the same study, indirect tensile (Brazilian) tests gave a lower tensile strength than direct tension tests with a ratio of $0.8: 1$, which indicates that the beam tests give a tensile strength that exceeds indirect tension values by a ratio of 2.9:1. Broadly in agreement, [5] showed that for 3 different rock materials, 2 (Bowral trachyte and Gosford sandstone) failed in three-point bending at approximately 2 times the load that would be predicted based on a tensile strength inferred from indirect tensile tests. The final rock tested by Jaeger (Carrara marble) failed 
in three-point bending so as to suggest a tensile strength that is 1.35 times higher than what would be inferred from indirect tensile (Brazilian) tests. Note that because of the difference between tensile strength inferred from indirect and direct tension tests, the legitimacy of indirect tensile (Brazilian) tests has been the subject of debate [7], [8].

In order to provide what is, to our knowledge, a first set of relevant data for the dependence of static fatigue on loading configuration, we present here tensile static fatigue test results for a South Australian Gabbro corresponding to three different loading configurations: three-point bend, fourpoint bend and indirect tensile (Brazilian) testing. The chosen configurations bear the similarity that all subject a portion of the specimen to a certain tensile stress that is readily computed. The specimens differ mainly in regard to the gradient of the stresses around the region that is subjected to the nominal maximum tensile stress. Namely, the three-point bending configuration produces a strong stress gradient and therefore a relatively small region that is subjected to the nominal maximum tensile stress. The four-point bending produces a somewhat more uniform stress distribution around the region subjected to the maximum tensile stress. Finally, the indirect tensile (Brazilian) configuration produces the largest proportion of the specimen that is subjected to a tensile stress that approximates the nominal maximum tensile stress.

In this context, the working hypothesis of this research is that the difference in the stress gradient near the point subjected to the maximum tensile stress will have a first order impact on time to failure in the context of an underlying stochastic mechanism of failure driven by the largest flaw that happens to be present in the maximally-stressed region. This hypothesis parallels a popular explanation for the observed dependence of measured tensile strength of rocks on the size of the specimen [9], [10].

\section{Method}

Static fatigue tests are conducted by applying a sustained static load to a specimen to induce a stress that is less than would cause instantaneous failure. After a time, the specimen fails as a result of the subcritical stress on the rockmass. It has been observed that there is a correlation between the imposed tensile stress and the time to failure for rocks that can be described by either a power law or an exponential relationship. The power law model is based on observation [11] while the exponential law draws theoretical origins from kinetics [12]. When the power law exponent is large enough (greater than, say, 10 or 20) the power law model become experimentally indistinguishable from the exponential law.

All experiments were conducted on specimens of an Australian Gabbro marketed as Adelaide Black Granite. The quarry for the material is located at Black Hill, about 100 kilometers North East of Adelaide in South Australia [13]. This material has been utilized in a range of experimental campaigns [14], [15] and the (static) mechanical properties have previously been characterized as presented in Table 1.

Table 1 - Material Properties of Adeliade Black Granite

\begin{tabular}{|c|c|c|}
\hline Property & Value & Unit \\
\hline Elastic Modulus & 102 & $\mathrm{GPa}$ \\
\hline Poisson's Ratio & 0.27 & \\
\hline Fracture Toughness & 2.5 & $\mathrm{MPa} \cdot \mathrm{m}^{0.5}$ \\
\hline Density & 3065 & $\mathrm{~kg} / \mathrm{m}^{3}$ \\
\hline Typical grain diameter & $1-10$ & $\mathrm{~mm}$ \\
\hline
\end{tabular}


As Adelaide Black Granite is a brittle material that is much stronger in compression than tension, each of the following three experimental configurations resulted in tensile failure of the material: three-point bend, four-point bend and indirect tensile (Brazilian) tests.
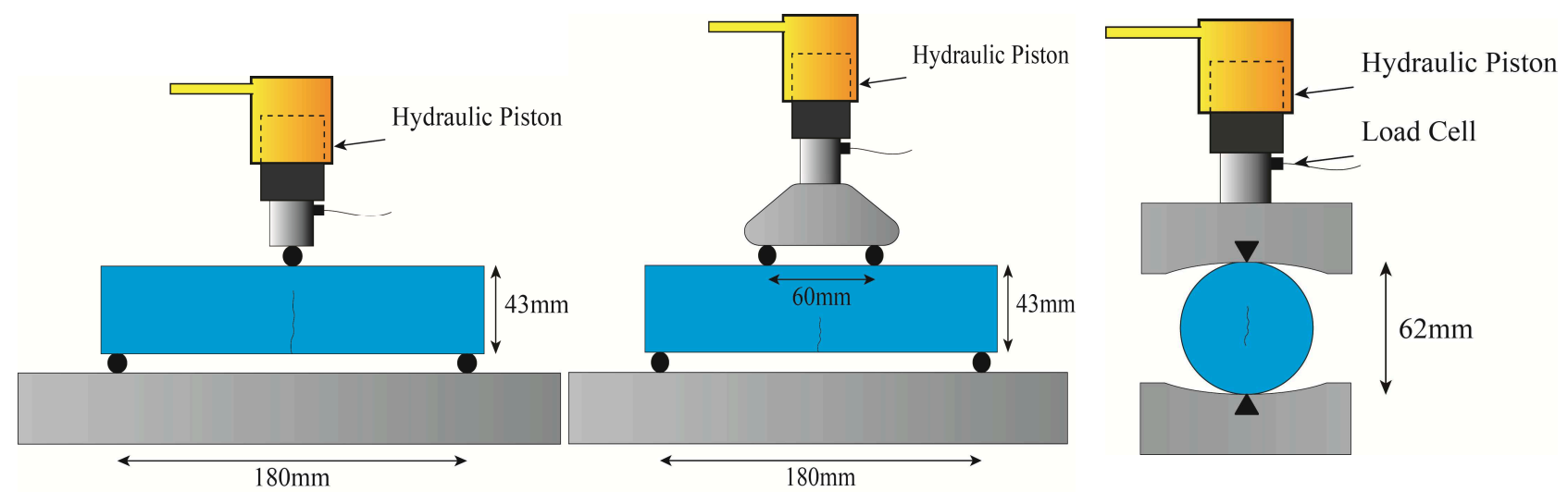

Figure 1 - Sketches of test configurations. Three-point bend (left), Four-point bend (centre), Indirect tensile (right)

In each configuration, a load was applied to dry specimens open to the laboratory atmosphere using a hydraulic piston with an effective area of $1 \mathrm{in}^{2}\left(645 \mathrm{~mm}^{2}\right)$, pressurized with an ISCO 260D syringe pump. In all cases, a seating load of approximately $260 \mathrm{~N}$ was applied in the minutes prior to application of full load. Load was always increased from the seating load to full load over a period of 12 seconds. Therefore a typical tensile stress rate would be in the order of $1 \mathrm{MPa} / \mathrm{second}$. Time to failure was counted from the application of maximum loading. Tests were conducted in a temperature-controlled laboratory at $21^{\circ} \mathrm{C} \pm 1^{\circ} \mathrm{C}$. Piston pressure (and therefore loading force) was actively maintained by the ISCO pump for the duration of each experiment.

Sample Loading. Each test configuration subjects a certain region of the specimen a tensile stress. The magnitudes of these tensile stresses and the stress distribution vary between the loading methods. Three and four point bending are simple cases where the maximum bending moment corresponds to the region of maximum tensile stress. The bending moments along the beam in each case are shown in Fig. 2 below.
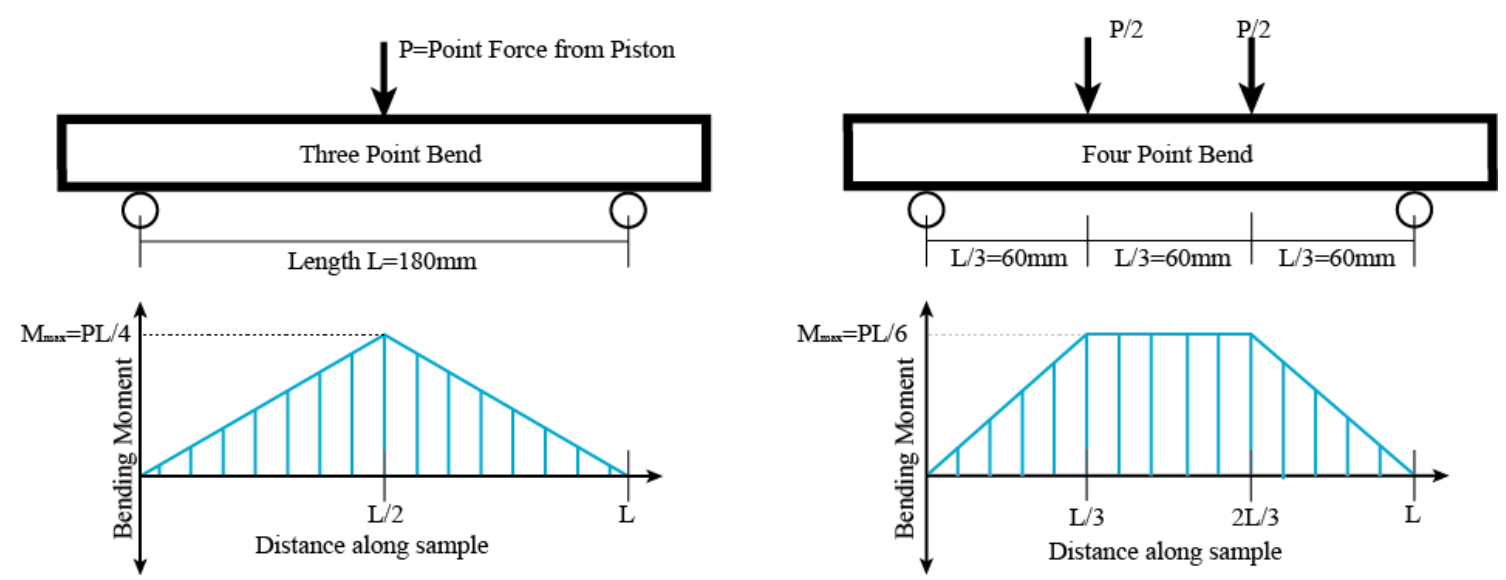

Figure 2 - Loading configurations and bending moments exerted on three-point and four-point bend samples

A homogeneous brittle beam with significantly lower tensile strength than compressive strength that is subject to bending will fail in the region under tension. For the three-point and four-point beam tests, the region of maximum tensile stress occurs in the lowest fibers of the beam as shown in Fig. 3. Note also that three-point bend tests subject the central portion of the specimen to shear stresses 
as well and therefore are not considered valid for applications such as the testing of strength of polymer bonded interfaces [16] which is well-known to be sensitive to mixed-mode loading.

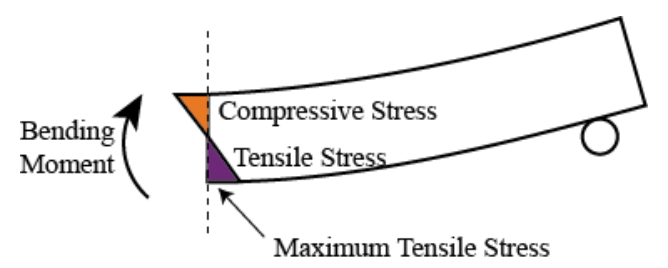

Figure 3 - Stresses exerted on a beam under bending

Maximum tensile stress $\left(\sigma_{t}\right)$ on a solid rectangular beam specimen subject to three-point or fourpoint loading is calculated as follows:

Three-point

$$
\sigma_{t}=\frac{3 P L}{2 h d^{2}}
$$

Equation 1

$$
\text { Four-point (L/3 load spacing) } \quad \sigma_{t}=\frac{P L}{h d^{2}}
$$

Equation 2

where $\sigma_{t}$ is the maximum tensile stress, $P$ is the applied force, $L$ is the support width, $h$ is the thickness of the specimen and $d$ is the height of the specimen.

The indirect tensile (Brazilian) test configuration causes the sample to fail in a region of tensile stress exerted on a diametral line between a compressive load and reaction point on a disc specimen [17]. The maximum tensile stress exerted on an indirect tensile test specimen is calculated as follows:

$$
\text { Indirect Tensile test } \quad \sigma_{t}=\frac{2 P}{\pi h D}
$$

Equation 3

where $P$ is the applied force, $h$ is the thickness of the specimen and $D$ is the diameter of the specimen.

\section{Results}

A total of 38 tests were run in the three configurations. A combined plot of all results is presented in Fig. 4 while individual plots by configuration and test result data tables are contained in Appendix A: Test Data.

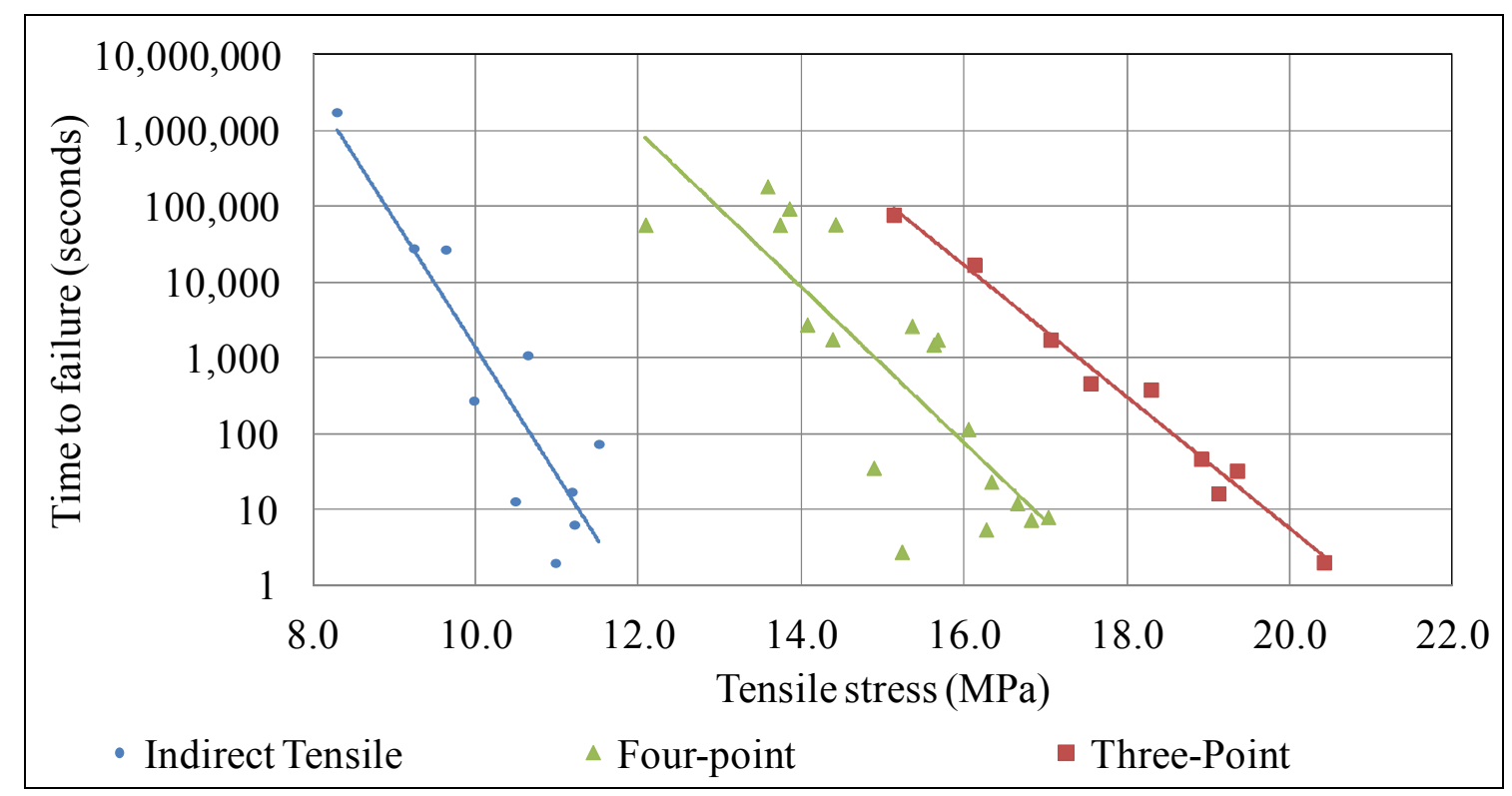

Figure 4 - Results from each configuration with related fitted exponential relationships (solid lines) 
As can be seen in Fig. 4, tests performed in a three-point bend configuration produced a relationship between time to failure and the applied tensile stress that could be accurately predicted by a best-fit exponential relationship, achieving an $\mathrm{r}^{2}$ value greater than 0.95 (Table 2). A similar quality of fit was obtained with a power law in this and all other cases. Because it is not possible to experimentally discern between power law and exponential relationship we will henceforth present only the exponential best-fit curves and restrict our discussion to the comparison among the test results.

The dependence upon loading configuration can firstly be observed by examining tests of the samesized beams loaded in a four-point bend configuration. These consistently failed earlier at a given nominal tensile stress than otherwise identical three-point tests. Also the results of four-point bend testing were more scattered and therefore were not as well represented by an exponential (or power law) relationship relating time to failure with the applied tensile stress $\left(\mathrm{r}^{2}<0.7\right)$.

Finally, indirect tensile (Brazilian) tests failed the earliest for a given calculated tensile stress. The exponential (or power law) relationship between the time to failure and the applied tensile stress gave rise to $r^{2} \sim 0.80$, which is intermediate to the three and four-point bending, although the absolute magnitude of the scatter is similar to that encountered in four-point bending. We also note that the magnitude of the scatter for the indirect tension tests appears to be greater at larger loads, while no similar correlation is observed for the other two configurations.

Table 2 - Results Summary

\begin{tabular}{|c|c|c|c|}
\hline & Three-point bend & Four-point bend & Indirect tensile \\
\hline Specimen Size & $\begin{array}{l}\text { Height: } 40 \mathrm{~mm} \\
\text { Thickness: } 20 \mathrm{~mm} \\
\text { Support: } 180 \mathrm{~mm} \\
\end{array}$ & $\begin{array}{l}\text { Height: } 40 \mathrm{~mm} \\
\text { Thickness: } 20 \mathrm{~mm} \\
\text { Support: } 180 \mathrm{~mm} \\
\end{array}$ & $\begin{array}{l}\text { Diameter } 62 \mathrm{~mm} \\
\text { Thickness } 28 \mathrm{~mm}\end{array}$ \\
\hline Number of tests & 9 & 18 & 10 \\
\hline $\begin{array}{l}\text { Exponential fitting parameters } \\
\qquad t=a \cdot e^{b \sigma_{t}}\end{array}$ & $\begin{array}{c}a=1.32 \times 10^{18} \\
b=-2.00\end{array}$ & $\begin{array}{c}a=2.13 \times 10^{18} \\
b=-2.368\end{array}$ & $\begin{array}{c}a=1.14 \times 10^{20} \\
b=-3.894\end{array}$ \\
\hline Goodness of fit (exponential) & $r^{2}=0.98$ & $r^{2}=0.67$ & $\mathrm{r}^{2}=0.80$ \\
\hline $\begin{array}{l}\text { Power law fitting parameters } \\
\qquad t=a \cdot \sigma_{t}^{b}\end{array}$ & $\begin{array}{l}a=4 \times 10^{46} \\
b=-35.16\end{array}$ & $\begin{array}{l}a=3 \times 10^{43} \\
b=-34.49\end{array}$ & $\begin{array}{l}a=7 \times 10^{41} \\
b=-38.81\end{array}$ \\
\hline Goodness of fit (power law) & $r^{2}=0.98$ & $r^{2}=0.66$ & $\mathrm{r}^{2}=0.81$ \\
\hline $\begin{array}{c}\text { Predicted tensile stress for } \\
\text { time to failure of } 1 \mathrm{~s} \\
\text { (approx instantaneous failure) }\end{array}$ & $20.7 \mathrm{MPa}$ & $17.8 \mathrm{MPa}$ & $11.9 \mathrm{MPa}$ \\
\hline $\begin{array}{l}\text { Predicted tensile stress for } \\
\text { time to failure of } 1 \times 10^{16} \mathrm{~s} \\
\text { or } 317 \text { million years } \\
\text { (See discussion section) }\end{array}$ & $2.4 \mathrm{MPa}$ & $2.3 \mathrm{MPa}$ & $2.4 \mathrm{MPa}$ \\
\hline
\end{tabular}

\section{Discussion}

The dependence of both the coefficient and the power law exponent (or the scaling of the quantity in the argument of the exponential law) on the testing configuration is consistent with a conceptual explanation that can be partially borrowed from critical load testing of rocks wherein the failure is controlled by the largest flaw in the region that is subjected to the maximum tensile stress (needs 
citation). Essentially the difference is that for macroscopic static fatigue failure one must consider that the dominant flaw can grow subcritically. Hence the size of the area subjected approximately to the maximum tensile stress is proposed to exert first-order control on the measured static fatigue behavior. In particular, the maximally-stressed region in the three point bend test is likely to contain a smaller dominant flaw than the four-point and indirect tension tests, which subject a larger region to the maximum tensile stress. This conceptual model is thus consistent with the tendency for three point bending to sustain the same maximum tensile stress for a longer time prior to failure than the other two methods.

If the instantaneous failure is taken as the extrapolated stress corresponding to a time to failure of $\sim 1$ second, then three-point bending, four-point bending, and indirect tensile tests produce tensile strengths of 21,18 , and $12 \mathrm{MPa}$, respectively. These results give a ratio of 1.75:1 between threepoint and indirect and 1.5:1 between four-point bending and indirect and are therefore consistent with prior experiments that considered only instantaneous failure loads [4], [5]. For comparison, the stresses corresponding to failure after 100,000 seconds ( $\sim 1$ day) are 1.67:1 and 1.44:1 for threepoint and four-point to indirect, respectively. These ratios are slightly smaller than the instantaneous ratios, indicative of the differences in the slopes.

An interesting curiosity is observed if all three lines are extrapolated. An approximately common point of intersection, as shown in Table 2 row 9, suggests that that predicted stress corresponding to failure after 300 million years is $\sim 2.4 \mathrm{MPa}$, regardless of the testing configuration. Note that this timescale is potentially geologically relevant and would be associated with failure at tensile stresses that are $\sim 20 \%$ of the tensile strength inferred from indirect tension tests. This intersection of the fitted curves seems to have no practical relevance, rather is something of a curiosity.

This study has focused on a single crystalline rock. However, Jaeger [5] observed that configurational dependence varies by material. Hence, expanding these experimental results to different rock types will comprise an essential component of establishing an experimental basis from which statistical static fatigue theories can be tested.

\section{Conclusions}

This paper presents results from static fatigue tests conducted under three different configurations designed to cause delayed tensile failure in Gabbro specimens. Results spanning five to six orders of magnitude of time were obtained using three-point bending, four-point bending, and indirect tension (Brazilian) experiments. The main observations are as follows:

1) The time to failure at a given load is greatest for three-point bending and smallest for indirect tension,

2) The decrease in the time to failure for a given increase in stress is greatest for indirect tension and least for three-point bending,

3) The scatter of the results about the best-fit curve is the least for three-point bending,

4) The results do not clearly discern between exponential and power-law relationships between time to failure and nominal applied tensile stress,

5) The best-fit exponential laws obtained for each of the three test series imply an approximately common intersection point at $\sim 300$ million years at a loading that is $\sim 20 \%$ of the tensile strength that would be inferred from indirect tensile tests.

The observations are broadly consistent with a hypothesis that extends the well-known "largestflaw" principle that has been previously used to explain the dependence of laboratory value of tensile strength on specimen size. In particular, the three-point bending arrangement can be understood to subject the smallest region to a tensile stress that is near the maximum tensile stress 
while the indirect tension arrangement produces the most uniform region subjected to a tensile stress near the nominal maximum.

Ongoing work is aimed at understanding not only the configurational dependence, but also the size dependence on measured static fatigue properties. These issues are vital for utilizing laboratory measurements in the field for prediction of time and size dependent failure of underground structures such as rock pillars in mines and the mobilization of faults in the Earth's crust. Furthermore, it is anticipated that a rich data set that includes size and configurational dependence may provide an experimental pathway to resolving the long-held debate regarding whether the time to failure versus the applied stress is best described by an underlying model that leads to a power law or one that leads to an exponential relationship.

Appendix A: Test Data

Table 3 -Three-point bend results

\begin{tabular}{|c|c|}
\hline Tensile stress & Time to failure \\
\hline$(\mathrm{MPa})$ & (seconds) \\
\hline 20.4 & 2 \\
\hline 19.1 & 17 \\
\hline 19.4 & 34 \\
\hline 18.9 & 49 \\
\hline 18.3 & 396 \\
\hline 17.6 & 475 \\
\hline 17.1 & 1,793 \\
\hline 16.1 & 17,626 \\
\hline 15.1 & 79,920 \\
\hline
\end{tabular}

Figure 5 - Plot of three-point bend results

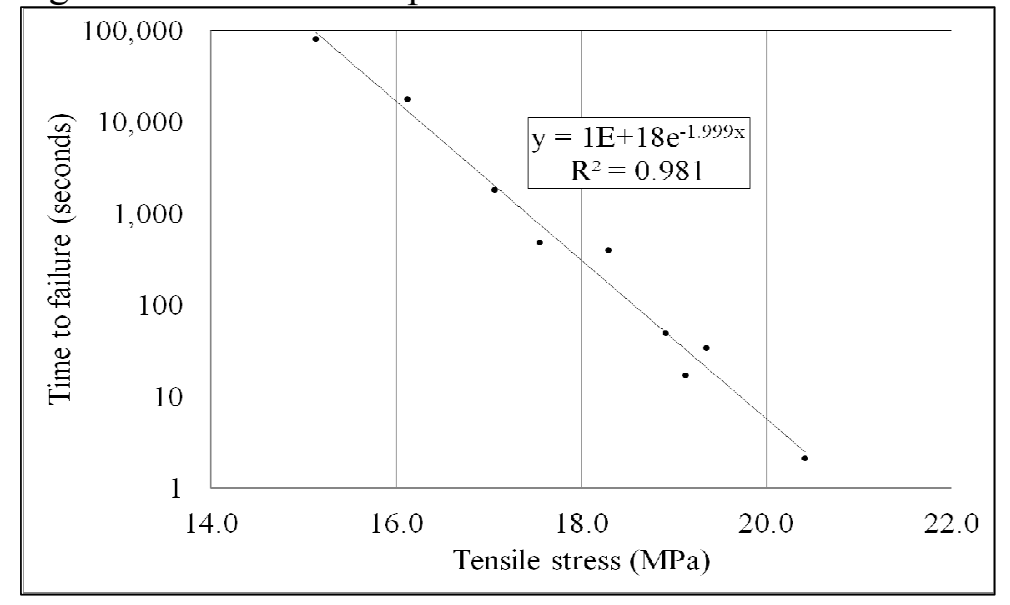

Table 4 - Four-point bend results

\begin{tabular}{|c|c|}
\hline Tensile stress & Time to failure \\
\hline Mpa & seconds \\
\hline 15.2 & 3 \\
\hline 16.3 & 6 \\
\hline 16.8 & 8 \\
\hline 17.0 & 8 \\
\hline 16.7 & 13 \\
\hline 16.3 & 24 \\
\hline 14.9 & 37 \\
\hline 16.1 & 119 \\
\hline 15.6 & 1,554 \\
\hline 15.7 & 1,806 \\
\hline 14.4 & 1,823 \\
\hline 15.4 & 2,722 \\
\hline 14.1 & 2,851 \\
\hline 13.7 & 58,836 \\
\hline 12.1 & 59,184 \\
\hline 14.4 & 60,048 \\
\hline 13.9 & 96,768 \\
\hline 13.6 & 190,080 \\
\hline
\end{tabular}

Figure 6 - Plot of four-point bend results

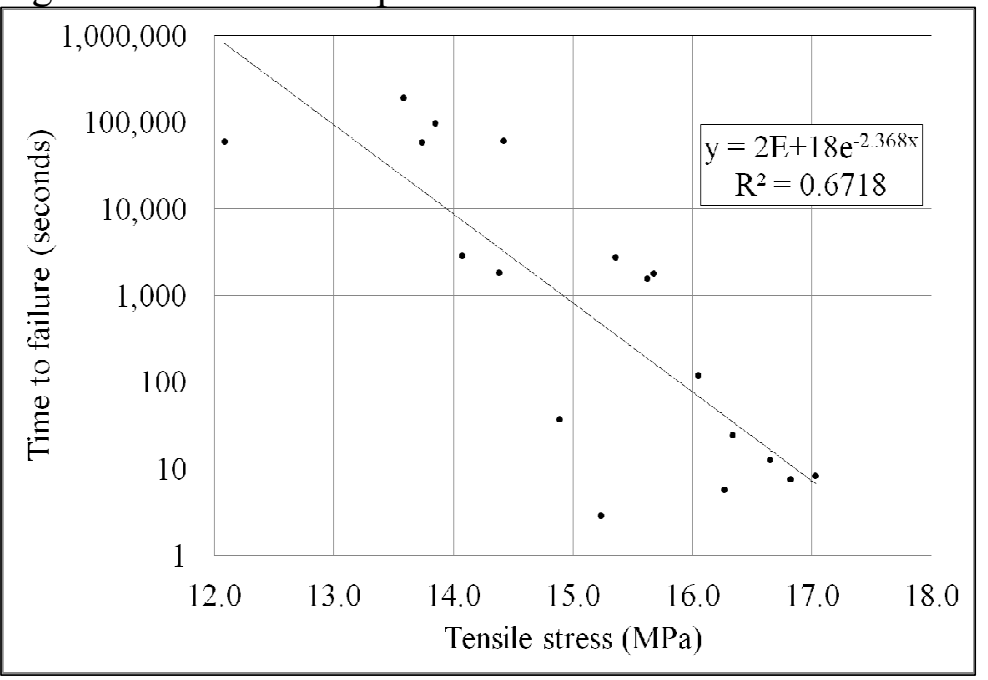


Table 5 - Indirect tensile results

\begin{tabular}{|c|c|}
\hline Tensile stress & Time to failure \\
\hline Mpa & seconds \\
\hline 11.0 & 2 \\
\hline 11.2 & 6 \\
\hline 10.5 & 13 \\
\hline 11.2 & 17 \\
\hline 11.5 & 74 \\
\hline 10.0 & 277 \\
\hline 10.6 & 1,098 \\
\hline 9.6 & 27,130 \\
\hline 9.3 & 28,134 \\
\hline 8.3 & $1,771,200$ \\
\hline
\end{tabular}

Figure 7 - Plot of indirect tensile results

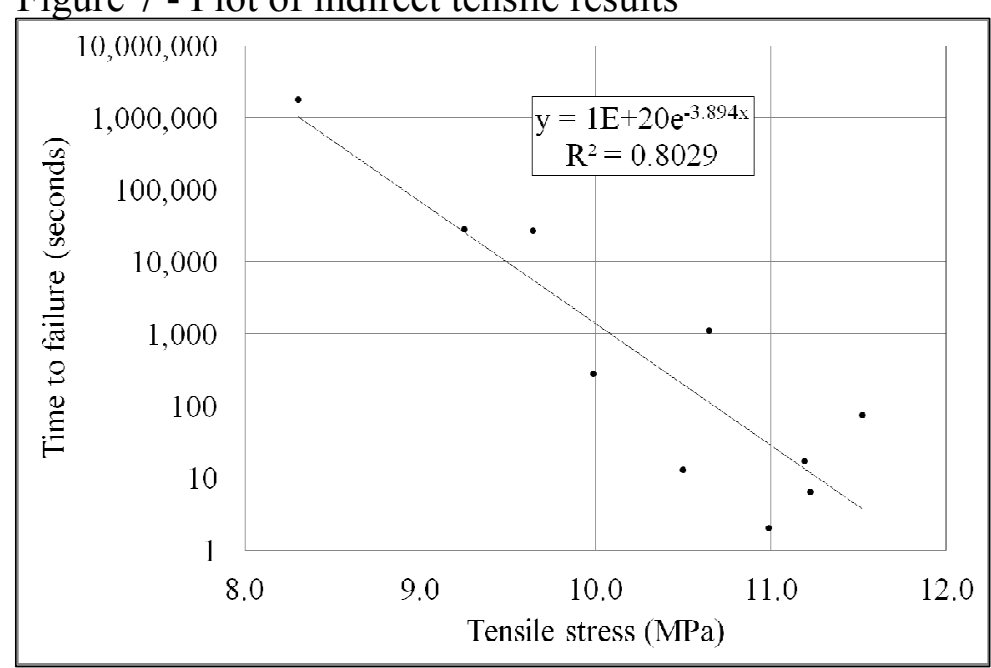

\section{References}

[1] C. H. Scholz, Static fatigue of quartz, J. Geophys. Res., vol. 77, no. 11, pp. 2104-2114, Apr. 1972.

[2] C. H. Scholz, The mechanics of earthquakes and faulting, 2nd Editio. Cambridge University Press, 2002.

[3] D. M. Cruden, The static fatigue of brittle rock under uniaxial compression, Int. J. Rock Mech. Min. ..., vol. 11, no. 2, pp. 67-73, Feb. 1974.

[4] R. Berenbaum and I. Brodie, Measurement of the tensile strength of brittle materials, Br. J. Appl. Phys., vol. 281, pp. 281-287, 1959.

[5] J. C. Jaeger, Failure of Rocks Under Tensile Conditions, Int. J. Rock Mech. Min. Sci., vol. 4, pp. 219-227, 1967.

[6] A. Cocurullo, G. D. Airey, A. C. Collop, and C. Sangiorgi, Indirect tensile versus two-point bending fatigue testing, Proc. ICE - Transp., vol. 161, no. 4, pp. 207-220, 2008.

[7] C. Fairhurst, On the validity of the 'Brazilian' test for brittle materials, Int. J. Rock Mech. Min. Sci. Geomech. Abstr., vol. 1, no. 4, pp. 535-546, 1964.

[8] D. Li and L. N. Y. Wong, The Brazilian Disc Test for Rock Mechanics Applications: Review and New Insights, Rock Mech. Rock Eng., vol. 46, no. 2, pp. 269-287, May 2012.

[9] A. Carpinteri, Decrease of apparent tensile and bending strength with specimen size: two different explanations based on fracture mechanics, Int. J. Solids Struct., vol. 25, no. 4, pp. 470-429, 1989.

[10] W. Weibull, A Statistical Theory of the Strength of Materials. Generalstabens litografiska anstalts förlag, 1939, p. 45.

[11] R. Gy, Stress corrosion of silicate glass: a review, J. Non. Cryst. Solids, vol. 316, pp. 1-11, 2003.

[12] S. N. Zhurkov, Kinetic concept of the strength of solids, Int. J. Fract., vol. 26, pp. 311-323, 1984.

[13] Adelaide Black Imperial information page, 2013. [Online]. Available: http://www.granitesofaustralia.com. [Accessed: 16-Sep-2013]. 
[14] A. P. Bunger, R. G. Jeffrey, J. Kear, X. Zhang, and M. Morgan, Experimental Investigation of the Interaction Among Closely Spaced Hydraulic Fractures, in American Rock Mechanics Symposium, 2011.

[15] A. V. Dyskin, E. Pasternak, A. P. Bunger, and J. Kear, Blue Shift in the Spectrum of Arrival Times of Acoustic Signals Emitted during Laboratory Hydraulic Fracturing, in Effective and Sustainable Hydraulic Fracturing, 2013, pp. 467-476.

[16] F. L. Matthews and R. D. Rawlings, Composite materials: Engineering and Science. 1999, p. 470.

[17] ASTM, Standard Test Method for Splitting Tensile Strength of Intact Rock Core Specimens, vol. 44, no. 0, pp. 0-4, 2013. 